\title{
Norovirus and Other Viral Gastroenteritis
}

Abstract

New and old entero-pathogenic viruses are increasing in the society and in the healthcare, like the Calicivirus family (Norovirus, Sapovirus, Astrovirus), Reovirus family (Rotavirus) (especially infant, toddler and elderly) and rarely other viral types such as adenovirus (especially serotype 40, 41), bocavirus, parechovirus, enterovirus and a variety of other types. In all types of gastroenteritis, infection prevention measures are performed as with norovirus, described below. The following chapter is focused on practical measures to detect and prevent transmission of entero-pathogenic viruses in healthcare institutions.

\section{Keywords}

Entero-pathogenic viruses · Norovirus · Sapovirus · Rotavirus · Viral gastroenteritis, enteritis, vomiting, diarrhoea · Abdominal pain, frequent bowel movements Admission control · Pre-examination · Information - Screening · Isolation · PPE Decontamination · Environment · Eradication · Nosocomial infections Infection control $\cdot$ Hygiene $\cdot$ Prevention

\subsection{Purpose}

- To prevent transmission of viral gastroenteritis to patients, staff and the environment.

- The infections are transmitted via contact, faecal-oral and/or air (droplets, aerosol).

- Actual virus types are norovirus, sapovirus, astrovirus, rotavirus and rarely other viral types such as adenovirus (especially serotype 40, 41), bocavirus, parechovirus, enterovirus and a variety of other types [1-4].

- For all types of viral gastroenteritis, infection prevention measures are performed as with norovirus, described below [4-7]. 


\subsection{Comprise}

All close contacts of patients (patients in the same room, personnel, visitors, etc.) All equipment, textiles, rooms and surfaces the patient has been in contact with.

\subsection{Responsibility}

The hospital's management provides written procedures for detecting, isolating and controlling infectious patients with norovirus and other infectious gastrointestinal viruses.

Department management implements guidelines and ensures that personnel, patients and visitors are informed of infection prevention measures in connection with outbreaks of norovirus and other viral gastroenteritis and reports to the Director about resource problems (personnel, expertise, isolates) that may expose other patients, personnel and visitors to infection.

Employees follow routines and guidelines for infection protection.

\subsection{Practical Measures}

\subsubsection{Routine at All Admissions/Outpatient Clinics/Day Surgery}

Preliminary examination: ask the patient, relatives, physician before admission if the patient has symptoms of gastroenteritis. This is especially important in periods of epidemics of norovirus and rotavirus; especially autumn and winter.

If suspected/confirmed viral gastroenteritis, there are at least two options: (a) postpone admission to the patients infection status is resolved; (b) admit and isolate the patient until infection status is clarified.

\subsubsection{Isolation and Other Preventive Measures [4-6]}

- Index patient is contact isolated with own toilet/shower and preferably own decontaminator. Avoid cohort isolation due to repeated outbreaks. The patient cannot walk into the corridor or common patient rooms but can walk directly out of the hospital.

- Patients exposed-have been in the same room as the index patient with symptoms - are isolated separately from the index case during incubation time for a minimum of 2-3 days [1-7]. Treat as possible infected.

- Personnel wear PPE (gown, gloves, surgical mask/cap (air transmission, especially when vomiting) and room-bound shoes that can be disinfected or shoe covers). Follow routines for taking off infection control equipment. Carefully remove any shoe covers with gloves on, and wash hands after wearing gloves. 
- The use of PPE must be properly implemented to prevent spread of infection. Taking on PPE is carried out in a defined clean area in the sluice of the isolate or on the corridor outside the patient room. Only clean equipment must be on the hallway!

- Wash or disinfect hands before donning.

- Gown (single use), long-sleeved cuff.

- Gloves pulled over the gown's cuff.

- Room-bound shoes (or disposable cover). Room-bound shoes should be machine-washed at $85^{\circ} \mathrm{C}$ or autoclaved.

- Surgical mask/cap.

- Taking off the PPE is carried out in the defined area of the isolate sluice or in the patient room at the exit door. Never doff in the corridor outside the isolate!

- If using shoe covers, these must be removed first. Gloves are used when gently removing the overcoat shoe deposited in contaminated waste.

- Remove the gloves; grab the left glove at the wrist (not higher up) and gently turn it inside out, and use the inverted glove as a cloth to grab through to remove (roll off) the remaining glove. Learn to remove gloves without contamination!

- Hand hygiene.

- The gown is taken off by opening behind the back (neck) — avoid touching the front and arms - pull the cuffs over the hands, and roll the gown gently along from the sides and from above downwards without touching the outer side. Place gently in the waste bag.

- Hand hygiene.

- Remove surgical mask/cap by loosening back on the head-not touching the front.

- The hands are finally washed with soap and water.

- Use eventually a "cloth" with chloramine $5 \%$ in the sluice for wiping off the shoes. Replace this for each shift.

- Norovirus and other intestinal pathogenic viruses attach easily to the skin [4, 8, 9] There may be a failure effect of both handwash and hand disinfection.

- Handwash with soap and water may work probably better than hand disinfection and is therefore used for norovirus [4-9]. Always wear gloves when there is suspected gastrointestinal infections, and perform hand hygiene before and after use of gloves!

- Personnel with symptoms report sickness and stay at home for at least 2 days after symptom freedom $[1,7]$.

- Inform all personnel and visitors.

- Visitors should follow procedures for using PPE and hand hygiene and should not stay in common rooms, corridors, etc. together with other patients/visitors. They may be infected with the same microbiological agent and spread the infection in the department. Visitors with symptoms should be at home until 2-3 days after freedom of symptoms (except for relatives of children and critically ill).

- Limit general access, and avoid thoroughfare.

- Limit surveys/treatment of the actual patients at other departments while the outbreak is going on. 


\subsubsection{Other Measures [4-6]}

- Exposed healthcare professionals should not work at other healthcare institutions or other departments before the outbreak is over.

- Hand hygiene is reviewed and sharpened. Alcohols have limited effects on norovirus. Therefore, important with glove use.

- Admission stop is considered, depending on the isolation conditions. Admission should be stopped for 48-72 $\mathrm{h}$ after the last new case with gastroenteritis (diarrhoea and/or vomiting).

- Discharge of patients who can manage at home should be considered. Do not discharge to other healthcare institution from the unit before $48-72 \mathrm{~h}$ after symptom freedom.

- Drinks and food service, etc. on the corridor are removed. The ice maker machine is emptied, decontaminated and washed. Should not be used during outbreaks at the department. Do not use common coffee machines, etc. on the corridor. No self-service.

- Report to infection control unit daily while the outbreak is going on.

- Closure and disinfection of wards. Occasionally, the entire department must be closed, emptied and disinfected. Particularly important are common service rooms, equipment stores, clean textile rooms, kitchens, etc.

\subsubsection{Sampling}

Preferably, only aqueous, loose faeces samples if not epidemiological examination. Faeces from patients in the acute phase and preferably within the first 3 days (up to 7 days) after the disease starts. Take samples from all cases during the primary outbreak, including personnel with symptoms. If the outbreak continues, sampling is unnecessary if the virus is already detected. 5-10 g faeces (a spoon) is sampled in a sterile test tube and sent immediately or stored in a refrigerator until sent to the laboratory (no more than 2 days).

\subsubsection{Disinfection of Rooms and Surfaces [4-7]}

Environment and equipment around the patients may be heavily contaminated by norovirus or other intestinal pathogens [4-7, 10, 11]. Norovirus may survive for more than a year in the environment if not removed and if the transmission dose is very low: 10-100 virus particles [1, 4]. All decontamination should be carried out thoroughly. Proper use of effective disinfectants as 5\% chloramine or $10 \%$ household bleaches (home) or peracetic acid is important [4, 7].

- Daily disinfection of all patient-related equipment and common touch points $\times 3$ with alcoholic wipes (eventually, chloramine $5 \%$ or household bleach $10 \%$ ). 
- Daily disinfection with 5\% chloramine; wipe over fixtures, door handles, off and on knots, the floor and all surfaces. Then use normal soap and water over the same surfaces immediately afterwards. See isolation regimens.

- Terminal disinfection of all rooms where the patient has stayed.

- Hydrogen peroxide gas/aerosol can be effective at terminal disinfection in an empty room [4, 12, 13].

\subsubsection{Isolation Period, Readmission, Transfers [4-7]}

- The patient is isolated throughout the hospital stay even after the diarrhoea/vomiting is stopped. Especially elderly can shed viruses for days to weeks after symptoms have disappeared, and up to $30 \%$ may be healthy virus carriers $[1,6$, 14-17].

- When transferring to another health institution, inform about norovirus infection and also for patients exposed to infection.

\subsection{Background Information}

New and old entero-pathogenic viruses are increasing in the society and in the healthcare and may cause large, global outbreaks. The Calicivirus family (norovirus, sapovirus, astrovirus) and the Reovirus family (rotavirus) (especially infant, toddler and elderly) are the most common. More rarely may other viral types such as adenovirus (especially serotypes 40 and 41), bocavirus, parechovirus, enterovirus and a variety of other types (including sars) cause outbreaks [1-4]. In all types of gastroenteritis, infection prevention measures are performed as with norovirus [4-7].

\subsection{Norovirus}

Small, round virus with high infectivity; $<10-100$ virus particles are enough to start a gastroenteritis [1, 4]. Norovirus (former Norwalk virus) is the cause of "winter vomiting disease" inside and outside institutions, especially winter time (see Fig. 54.1). There is large amount of virus in vomit and faeces $\left(10^{12}\right.$ viruses/gram faeces) during acute disease, and it is rapidly transmitted via vomiting; drops/aerosols; contaminated equipment, textiles, faeces, food and water; etc. [1, 4, 7]. Epidemics are especially associated with certain genotypes with more virulent viruses that develop and change over years $[1,4]$.

Norovirus is heat resistant, survives $75^{\circ} \mathrm{C}$, and is also resistant to a variety of disinfectants, including chlorine in lower concentrations, and survives dry for days to months (>10 months) on equipment, textiles, food and water and otherwise in the environment $[4,7-11,18]$. 


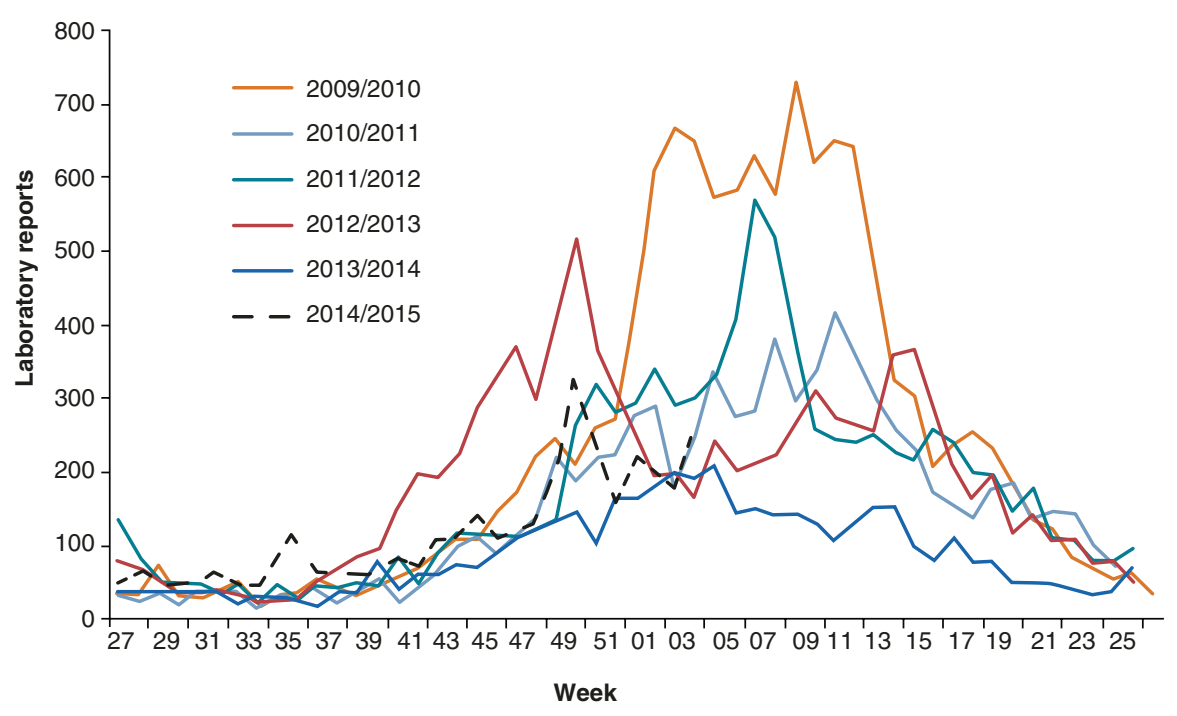

Fig. 54.1 Norovirus outbreaks causing closure of hospital wards in England: variation in seasons. In 2014, there were 690 outbreaks with closed wards in 640 cases. (Source: Public Health England. August 14, 2015) [23]

Mild disease symptoms occur in most patients, with short or no immunity, so repeated sickness may occur in the same patient, and there is no vaccine and no specific treatment. Up to $50 \%$ of a ward or department may start with symptoms approximately simultaneously (both patients and personnel) [4, 16].

Incubation time of 1/2-2 days may often start abruptly without any other symptoms other than vomiting.

Clinical symptoms: elderly and patients in a poor condition are more likely to have severe progression and longer diarrhoea and can shed viruses for a very long time [1, 4, 14, 17-19]. Symptoms include nausea, vomiting (2-3 days), diarrhoea (2-5 days), incontinence and fever $38-39^{\circ} \mathrm{C}$, of approximately $2-3$ days duration.

Reinfections and subclinical infections are common.

\subsubsection{Occurrence, Costs and Mortality}

Global spread pattern since 1995 with more than 300 million cases a year and has become a year-round disease, although the winter frequency increases over 200fold when people are closer together. The virus circulates in the environment and creates hyperendemic periods-especially in 2002, 2003, 2007 and 2010. In 2003, 23 million were sick of norovirus in the United States (12-13\% of the population), and CDC (Centers for Disease Control and Protection) estimates that 1 in 14 people becomes ill each year [4]. Nowadays approximately $40 \%$ of all foodborne 
infections are caused by norovirus. It is observed as a large problem in connection with outbreaks in cruise ship traffic; up to six consecutive cruises with the same boat have led to major outbreaks [4, 20-22]. CDC register cruises with norovirus outbreaks, and Norwegian ships are often involved [21].

The major epidemic waves in the society, schools, kindergartens, colleges, universities, passenger ships, hotels, conferences, trains, military camps, sports (Olympic ski sport in 2018), etc. are steadily further entering hospitals, nursing homes and other health institutions, often with long-lasting outbreaks: 19 days in hospital at average, 16 days in nursing homes and 7 days outside the health service [4, 14-17, 20-22].

Healthcare institutions with norovirus outbreaks lead to closure of departments and even hospitals. England is continuously registering outbreaks in hospitals [23]. In 2014 there were 690 outbreaks that resulted in closure of departments/units in 640 of the cases! In the first 4 weeks of 2015, there were already 62 outbreaks that all resulted in closure of the ward [23].

Norway is experiencing larger and smaller outbreaks, especially related to food and drink, international food trade and cruise boats [20-22, 24-26]. Also hospitals and nursing homes are strongly exposed to the infection [27, 28].

Outbreaks described in Norway from the Norwegian Institute of Public Health:

- 2001: Eikedalen, Hordaland; alpine resort, 400 were sick from drinking water.

- 2003: Bergen; seminar for health professionals, > 50 were ill.

- 2005: Oslo; 2 major outbreaks, 138 soldiers (starting with the kitchen staff) and 33 cases participating in a seminar after eating food from a catering company.

- 2006: Asker and Bærum; 17 were sick from eating oysters from France-part of an international outbreak.

- 2007: Stavanger; 81 were sick in 6 different parties with food from the same catering company.

- 2008: Oslo; 70 were sick in 6 different parties been on the same restaurant. Oysters from Ireland.

- 2008: Hamar; 150 were sick after hotel stay, kitchen staff infected.

- 2008: Ullensaker; more than 200 were sick at an airport hotel. Sick kitchen workers.

- 2009: Passenger ship from Oslo to Copenhagen; 36 were ill from 5 different sport teams (orientation). Some of these were probably sick in advance.

- 2010: National outbreak; Lollo lettuce from Denmark. At least ten outbreaks.

- 2010: Cruise ship from Oslo; springtime, several hundred were sick in three different trips from Oslo with "Vision of the seas". Several returns during the cruise.

- 2012: Oslo; 41 sick at "Christmas dinner" at a hotel. Infected oysters [24, 25].

- 2015: Cruise ship, on the Norwegian Fjords, May-June; 300 or more were probably sick [22].

- In addition, outbreaks at several healthcare institutions with 40-100 people involved per outbreak, almost as many personnel as patients. 


\subsection{Rotavirus}

The rotavirus is the most common cause of disease in small children and the elderly but can also cause epidemic outbreaks in the community and in healthcare institutions $[3,4] .40-60 \%$ of infant gastroenteritis is caused by rotavirus. $80-90 \%$ has had rotavirus infection at 4 years of age.

Clinical symptoms: acute vomiting, followed after a few hours of heavy diarrhoea with rapid dehydration and rapid, cholera-like diarrhoea with development of dehydration and loss of electrolytes, especially in the smallest children. Sunken fontanelle in infants, hollow orbital cavity and standing skin folds are classic signs of severe dehydration in toddlers. Infants/toddlers are admitted to hospitals for observation and rehydration.

If no prompt administration and treatment with intravenous therapy, it may lead to shock and death. It is estimated that 450-750,000 children die of rotavirus infection each year, globally. Vaccine is available.

Incubation period: 1-3 days

See also references [1-4] for more information.

\section{References}

1. Dolin R, Treanor JJ. Noroviruses and sapoviruses. In: Mandell GL, Douglas RG, Bennett JE, editors. Principles and practice of infectious diseases. 8th ed. London: Elsevier Churchill Livingston; 2015. p. 2122-7.

2. Dolin R, Treanor JJ. Astrovirus and picobirnaviruses. In: Mandell GL, Douglas RG, Bennett JE, editors. Principles and practice of infectious diseases. 8th ed. London: Elsevier Churchill Livingston; 2015. p. 2128-30.

3. Dormitzer PR. Rotaviruses. In: Mandell GL, Douglas RG, Bennett JE, editors. Principles and practice of infectious diseases. 8th ed. London: Elsevier Churchill Livingston; 2015. p. $1854-64$.

4. Andersen BM. Gastrointestinal virus infections. In: Handbook for hygiene and infection control for hospitals. Part 1: microbiology and infection protection. Fagbokforlaget; 2014. p. $248-54$.

5. Andersen BM. Prevention of viral gastroenteritis norovirus and the like. In: Handbook for hygiene and infection control for hospitals. Ullevål University Hospital; 2008. p. 459-61.

6. Andersen BM. Prevention of viral gastroenteritis-norovirus and similar infections. In: Handbook for hygiene and infectious care for nursing homes, long-term institutions. Akademika forlag; 2013. p. 249-54.

7. CDC. Guideline for prevention and control of norovirus gastroenteritis outbreaks in healthcare settings. 2012. IX Appendices.

8. Kampf G, Grotheer D, Steinmann J. Effect of three ethanol-based hand rubs against feline calicivirus, a surrogate virus for norovirus. J Hosp Infect. 2005;60:144-9.

9. Tuladhar E, Hazeleger WC, Koopmans M, et al. Reducing viral contamination from finger pads: handwashing is more effective than alcohol-based disinfectants. J Hosp Infect. 2015;90:226-34.

10. Cheesbrough JS, Green J, Gallimore CI, Wright PA, Brown DW. Widespread environmental contamination with Norwalk-like viruses (NVL) detected in a prolonged hotel outbreak or gastroenteritis. Epidemiol Infect. 2000;125:93-8. 
11. Lee N, Chan MCW, Wong B, et al. Fecal viral concentration and diarrhoea in norovirus gastroenteritis. Emerg Infect Dis. 2007;13:1399-401.

12. Andersen BM, Rasch M, Hochlin K, Jensen FH, Wismar P, Fredriksen JE. Decontamination of rooms, medical equipment and ambulances, using a dry fog or hydrogen peroxide disinfectant. J Hosp Infect. 2006;62:149-55.

13. Andersen BM, Hochlin K, Daling JP. Cleaning and decontamination of reusable medical devices, including the use of hydrogen peroxide gas decontamination. Microbiol Biochem Technol. 2012;4:57-62.

14. Gaspard P, Ambert-Balay K, Mosnier A, et al. Burden of gastroenteritis outbreaks: specific epidemiology in a cohort of institutions caring for dependent people. J Hosp Infect. 2015;91:19-27.

15. Thouillot F, Delhostal C, Edel C, et al. Gastroenteritis outbreaks in elderly homes in the east of France during winter 2009/10: aetiology research for a series of 37 outbreaks. Euro Surveill. 2012;17(9):pii: 20103.

16. Harris JP, Lopman BA, O'Bien SJ. Infection control measures for norovirus: a systematic review of outbreaks in semi-closed settings. J Hosp Infect. 2010;74:1-9.

17. Aoki Y, Suto A, Mizuta K, Ahiko T, Osaka K, Matsuzaki Y. Duration of norovirus excretion and the longitudinal course of viral load in norovirus-infected elderly patients. J Hosp Infect. 2010;75:42-6.

18. Barker J, Vipond IB, Bloomfield SF. Effects of cleaning and disinfection in reducing the spread of norovirus contamination via environmental surfaces. J Hosp Infect. 2004;58:42-9.

19. Gustavson L, Andersson LM, Lindh M, Westin J. Excess mortality following communityonset norovirus enteritis in the elderly. J Hosp Infect. 2011;79:27-31.

20. Vivancos R, Keenan A, Sopwith W, et al. Norovirus outbreak in a cruise ship sailing around the British Isles: investigation and multi-agency management of an international outbreak. J Infect. 2010;60:478-85.

21. Anonymous. Outbreak updates for international cruise ships. CDC 2015. 2015.

22. Mail on line. Passengers hit down by "horror" vomiting bug on Norwegian Fjords cruise vow never to go again "even if they paid us". 2015.

23. Anonymous. Suspected and laboratory-confirmed reported norovirus outbreaks in hospitals: outbreaks occurring in weeks 1-4. 2015. Public Health England. 2015.

24. Outbreak of norovirus infection in Norway. Institute of Public Health. 2009.

25. Steens A. Gastroenteritis outbreak during a "Christmas dinner" in a hotel in Oslo. December 2012. Public Health Institute. 2013.

26. Evanger N. Norwalk virus outbreak from marzipan cake. MSIS. 2002;30:32.

27. Andersen BM. Norovirus gastroenteritis - a challenge in and outside health institutions. Tidsskr Sykepleien. 2003;39.

28. Andersen BM, Størvold G, Vainio K. Norovirus gastroenteritis at Ullevål University Hospital. Tidsskr Nor Legeforen. 2003;123:1239. 